In many cases, the successive steps in the phenomena are not separately perceptible; but in the study of mental states,we do not question the succession of phenomena, although highly favourable instances only present them in their proper order.

21. With great circumspection in the choice of apparatus, and the amount of ether-vapour administered, it is possible, in many cases, to operate on the patient without loss of mental consciousness. The nature of the operation will be the best guide in attempts of this kind. In other cases, in order to avoid inconvenience from the jerks and contractions arising from reflex actions, total insensibility is desirable.

22. The theory of etherization advanced above, affords us many striking and instructive analogies with the action of other well-known agents-belladonna on the iris, infusion of tobacco on the leart, the Wourali poison. The last, as is well known, paralyzes the respiratory system of nerves, and destroys life by suspending the act of breathing. If an animal under its influence be made to breathe by an artificial force, the respiratory nerves awake from their temporary lethargy, and the animal lives.

22 . After consciousuess has been fully suspended by ethervapour, the several parts of the nervous system resume their functions successively. Music is heard before the patient sees, mental consciousness is restored before the sensibility to pain returns.

23. The action of ether-vapour on the ganglionic system, follows the sleep of voluntary and sensitive functions; the pulse is generally somewhat accelerated at first, especially when the vapour is very dilute; subsequently it lessens in frequency; ultimately, all parts of the system are reached, and life would be extinguished painlessly. This may be observed on small animals confined in ether-vapour.

Mortimer-street, Cavendish-square, April, 1847.

ON THE

USE AND ABUSE OF ISSUES, IN THE TREATMENT OF DISEASES OF THE JOINTS,

WITH A MORE FFEICACIOUS MODE OF EMPLOYING THEM.

By ANTHONY COLLING BROWNLESS, M.D., Physician to the Metropolitan Dispensary.

From some years' attentive observation of diseases of the joints, $I$ am convinced that, as a general rule, we liave no local remedial agent equally efficacious with caustic issues, in the treatment of these cases, and that they may be applied with greater benefit than any other counter-irritant, in almost every form of clironic disease of the joints, (whether commencing in the synovial membrane, cartilages, or bones,) provided they be employed under those conditions, and at those stages of each particular form of disease, in which this class of remedies may be judiciously used; and provided also, that the mode of action of the remedy be rightly understood by the practitioner, in order that it may be applied by him in a manner calculated to produce beneficial results.

To say all one could wish on the subject of issues, and their employment in the diseases of the joints, would not only require more space than the ordinary length of a paper would permit, but would necessarily involve a consideration of the nature and treatment of the special forms of these diseases, which could only be done in a systematic treatise. My object, in the present paper, is to make some practical remarks on this remedy, which will, for the most part, apply equally to its use in all the chronic affections of joints, and which have at least the value of being founded on the observation of a large number of cases. After pointing out, therefore, what I conceive to be the too common abuses of issues, and the evil consequences resulting from those abuses, $I$ will mention the manner of using this remedy, which experience has convinced me to be most efficacious, and which has impressed me very strongly, with its greater relative value, compared with other counter-irritants, and much earlier and more general applicability in almost all affections of joints, than is commonly attributed to it by many of the best authorities on these diseases. I will afterwards attempt to explain what appears to me to be the action and value of the remedy, when used after the plan which $I$ advocate.

Issues are too commonly used in these cases in a manner which would lead one to suppose, that those who employed them belonged to the ranks of the humoral pathologists; they are often made of large size, ${ }^{*}$ and kept open by foreign bodies

* I have lately seen, in Pitcairn's ward, St. Bartholomew's Hospital, a man another of pur metropolitan hospitals, had had two issues nade for the cure placed in them, which occasion a profuse discharge of pus; and from what we read in some high authoritics, it appears that it is for the purpose of procuring this discharge of pus that the issues are established, and that from it we are to expect the beneficial effects of this remedy. Now, when an issue is formed in a plethoric person, to relieve congestion of the brain, a free discharge of pus, kept up by means of it, will probably very well fulfil the intention for which it was employed; but in patients labouring under chronic affections of joints, and especinlly those of a scrofulons habit, the chylopoietic organs are commonly deranged in their functions, and the process of assimilation is much impaired, consequently, we find the system in a condition very ill capable of bearing any considerable drain upon it; and reason would indicate to us, that the establishing any such drain upon the general powers of the system, instead of benefiting the local affection, must be more likely to aggravate it, by tending to keep up or increase the very state of constitution, on which, in many cases, the local malady depends. What might rationally be inferred is certainly the fact, and I may confidently state, that in the treatment of chronic diseases of joints the use of large issues, kept open with peas or other foreign substances, and from which there is a continual and often very profuse discharge, is certainly most injurious, instead of beneficial, weakening the powers of the pationt, and thereby oftentimes destroying the chance of a desirable termination of the disease, which depends so much, in scrofulous cases, especially on improvement of the general health.

But besides the evils resulting from the drain upon the constitution, there is another, which arises from the manner of procuring the discharge, and which is little less objectionable. Peas and foreign bodies, inserted into issues for the purpose of keeping them open, frequently excite very considerable constitutional disturbance, and this, it is to be remembered, in a state of the system in which all sources of irritation should be sedulously avoided. No one who has had any practical acquaintance with the matter can deny the suffering and constitutional disturbance to which this mode of keeping issues open often gives rise; and when the general state of the constitution, in the majority of cases of diseased joints, is considered, we have sufficient evidence that the irritation thus caused must be highly injurious to the patient. Some may think that the irritation attendant upon the introdnction of peas or other foreign bodies into issues subsides in a few days, and that afterwards no more inconvenience is experienced from them. But the latter supposition is not the fact; for although after a few days the pain and irritation may probably subside, if the patient be not of peculiarly irritable constitution, yet this is by no means for a permanency; for it is well known that ulcers vary according to the state of the general health, and issues are not exempt from the changes that other ulcers undergo under similar circumstances. Thus, if we watch issues kept open for a length of time, we find them not infrequently presenting the character of irritable ulcers, with jagged, undermined edges, a thin bloody discharge, and excessively painful, the slightest touch causing the patient much suffering. In some persons, and under particular states of the constitution, we find them presenting a phagedænic appearance. No one will, $I$ think, deny that the presence of foreign bodies in ulcers of this kind must be a source of much irritation to the constitution generally. In some of the cases where great discharge has been kept up from large issues, these ulcers and the general system act and react upon each other with most mischievous results; the drain upon the system induces an enfeebled and irritable condition of it; this state of the constitution reacts upon the ulcer, causing it to secrete less, and become bleeding and painful, which agaim reacts for evil upon the general system. The great difficulty sometimes experienced in closing ulcers, the remains of large issues of long standing, may be mentioned as a proof of the weakened and irritable state of the constitution, to which they not infrerinently give rise. I need hardly say that issues followed by such results as I have mentioned above must be very hurtiful instead of beneficial. I believe that in the treatment of diseased joints, the lieeping issues open by foreign bodies placed in them is never either necessary or judicious, and frequently most injurious. Although $I$ lave been speak. ing of caustic issues, the same objections will hold good in reference to issues made in any other way. Many persons are fond of forming an issue by placing peas in the excavation of a tartarized antimony pustule, or on a blistered surface, and keeping them down by means of a piece of sheet lead. I

of his disease, in quick succession, on either side of the joint, each issue being of the size of an ordinary man's hand. I mention this, however, not as a common, butas a most unique mode of treatment. 
have seen excessive pain and irritation of the absorbent system produced by such proceedings, and therefore cannot too strongly condemn the practice; for the same reasons, where issues are needed in the treatinent of diseased joints, $I$ should never think of establishing them with the scalpel and peas, although $I$ have had but little experience in this kind of issue. The objections to the use of foreign bodics in issues will apply equally where the eschar is formed by the moxa, and peas are introduced when the slough has separated-a practice which, I am informed, is adopted in one, at least, of our metropolitan hospitals.

of the evils resulting from the use of foreign bodies in issues I have no doubt; and to prove that the practice is a common one I think I need only refer my readers to the article on issues in Mr. Samuel Cooper's "Surgical Dictionary" -a work so highly and deservedly esteemed as an accurate summary of surgical opinions, both past and present, that its evidence must have weight. After a very full descrintion of the management of issues by the insertion into them of beans, peas, or beads, as the general and most approved plan, and describing the best mode of retaining them in their places, and keeping the issue open by pressing on them with sheetlead and a bandage, Mr. Cooper adds-"Sometimes, however, the method of applying the caustic from time to time is preferred to the use of peas, on the ground of greater efficacy;" showing very clearly that the use of issues without peas is quite the exception to the rule as regards the profession gencrally. To show also the general use of large issues, I may quote the same author, who, speaking of the treatment of scrofulous disease in joints, says - "Such issues are commonly made on each side of the diseased joint, and of about the size of half-a-crown," which are to be liept open with peas, \&c. Another passage in the article "Moxa" shows the opinion, which is general, of issues not benefiting until after a discharge is established from them. It is the following:- "Issues and setons produce but little instantaneous effect; their efficacy therefore depends on the irritation and discharge daily kept up." And again, in the article "On Diseases of Joints," when speaking of counter-irritant remedies, Mr. Cooper remarks_- We must therefore impute a great degree of efficacy to the maintenance of a purulent discharge from the vicinity of the diseased part."

Sir Benjamin Brodie's great experience, however, leads him to take a different view of the action of issues, for which I will refer my readers to page 147 of the fourth edition of his "Observations on Diseases of the Joints;" and the manner of employing the remedy to which this distinguished surgecm gives the preference, confirms the usefulness of the plan which I am about to mention, although $I$ differ from him as to the mode of action of this remedy.

I would recommend, instead of using the remedy in the manner which I have condemned in the foregoing paragraphs, a method which, as I shall presently attempt to explain, seems to have reason on its side, and of the great value of which $I$ have fully satisfied myself by experience.

Issues should be made of moderate size, and before the effects of the one first made are lost by the process of repair of the ulcer being completed, another should be made at a distance from the former, so as to act upon another part of the joint affected, (for here I may be allowed to mention that this is frequently required in joints of considerable size, an issue on one side of a joint often relieving the side to which it is applied, but seeming to have little effect on the part of the joint remote from it.) Before the ulcer made by the lastformed issue is nearly healed, a fresh portion of skin should be destroyed by the caustic, and again and again should this proceeding be repeated, varying its position around the joint; and thus should a regular diversion from the diseased part be kept up.

There may be reasons in some cases for not carrying out this plan to tho letter as regards the destruction of fresli portions of skin on each application of the caustic. In such crises, or where the patient has great objection to it, a new plot of skiu need not be destroyed on each occasion that the caustic is used, but Sir B. Brodie's plan of frequently rubbing the old sore with caustic may be adopted; but, as a general rule I do not consider it so efficacious as the destruction of a fresh portion of skin, nor is the benefit so lasting, and, consequently, the caustic requires to be much oftener applied than where fresh skin is destroyed. Undoubtedly the latter is attended with more pain; but its duration is short, and it is not fol lowed generally by the irritative consequences of blisters and some other counter-irritants, or, I may add, of issues kept open by peas and pressure. Scars may be regarded as one inconvenience arising from this plan; but if we can obtain greater benefit to diseased joints by the application of the caustic to fresh portions of skin, the scars appear to me to be of trivial importance even in the case of the fair sex; for the joints commonly the seat of disease are, for the most part clothed, or at any rate may be kept so without any great drawback to the personal charms of any young lady.

The introduction of peas or other bodies for the purpose of keeping issues open I would in no case recommend. If from any cause it be judged fit to keep open the same issue, let it be touched with caustic, but not kept open even in this way for any great length of time, or it will become comparatively useless.

During the treatment of a very considerable number of cases in which I had the opportunity of employing issues in this way, $I$ found it to be the most efficacious mole of using them; and the principle, although not carried so far, has been fully confirmed in my mind, in a very extensive field for observation, by watching attentively, for several years, the patients under the care of Mr. Vincent, in St. Bartholomew's Hospital.

It is very rarely that this admirable surgeon keeps open an issue by peas, \&c.; he does not certainly, as a general rule, destroy a fresh portion of skin when a former issue is healingsometimes, perhaps generally, applying the caustic for a few times to the previous issue before destroying another portion of skin to form a new one; but the plan he adopts is in the main the same as I have recommended; for he uses moderate sized issues, seldom keeping them open with peas, and, consequently, frequently applies the caustic either to the old sores, or to the skin, to form new ones; and the happy results of his excellent practice have quite confirmed me in my dislike to the common, or, as it is called, " most approved," mode of employing this remedy, and in the value of its application in the manner which $I$ ain now recommending.

I conceive it is by the use of the remedy in this way that we may reasonably expect, and do obtain, the greatest amount of benefit from it in these cases, bccause it is not plethora we have to combat; our object is, not the conversion of as much blood as possible into excrete matters; the lowering the constitutional powers will only render the local malady more active; but we have a morbid and excited action of the vascular system in the diseased part; we wish to modify this action, to moderate this undue excitement, by inducing Nature to make a call upon the vascular system, which shall be at once sudden, urgent, and sufficiently durable. We wish (if I may be allowed so to speak) to give Nature a more useful field for her workmen, something better to do; we wish to change the sphere of her action by leading her from a diseased to employ herself in a healthy part, and by ourselves destroying a portion of healthy tissue, engage her powers in the processes of healthy restorative action, instead of in those of morbid changes and disorganization; and we would desire to do this with the least possible expenditure of the powers of the system generally, and in such a manner as is the least likely to produce constitutional irritation.

Patients experience the benefit of an issue very soon after it is made, if any benefit will be derived from it at all; long before any discharge is established from it. As soon as ever the call is made for the repair of the injury, we see the effect of the remedy. It is for us to keep up this effect, by again applying the caustic, before any ground is lost in the treatment of the disease, by the demand upon the vascular system becoming less urgent by the approach towards completion of the reparative process. By destroying fiesh portions of skin we are able to make the demand more imperious, and the effect of our application nore lasting.

I suspect parts may become habituated to local remedies as well as the constitution to general ones, so as to be little affected by them after long continuance; and if one may judge from experience, we may suppose such must be the case cometimes with old issues (aithough they may be large) which have long been kept open with peas; so that if they do not become the source of real evil, by inducing irritation, and the impairment of the constitutional powers, which $I$ think is most fiequently the case, we cannot expect much benefit from them

The very striking benefit almost always experienced immediately after the destruction of a fresh portion of skin by the caustic, with the continued improvement of the joint during its continued reapplication after the proper intervals, according to the princivles I have already explained, and, cceteris paribus, the little benefit generally felt from the long continuance of the same issue, especially if it be not frequently rubbed with the caustic, are to my mind quite conclusive as to the advantage of the first-mentioned plan. 
I have sufficiently contrasted this mode of employing issues with the common method; I will only add a few words on its value compared with some other counter-irritant remedies in general use.

Blisters are very liable, in many constitutions, to produce irritation, both constitutional and of particular orrans, and not infrequently considerable general fever, as well as swelling and pain of the part to which they are applied; the same disadvantages may be mentioned as more or less belonging to successive blisters-blisters kept open with savine cerate, the use of the ointment of tartarized antimony, and other counter-irritant remedies. T have had no experience in the use of setons in diseases of joints, but should suppose they were apt not infrequently to produce considerable irritation, and were liable, in several respects, to the same objections as issues kept open with foreign bodies. Looking carefully, therefore, at the ordinary effects of these various counter-irritants, I see all are liable at times to produce considerable constitutional disturbance, and according to my experience, much more frequently than caustic issues used in the manner. I have proposed. The question then suggests itself-Have they any advantages over issues in effecting a cure of these diseases? or may they be used when issues cannot?

With the exception of those cases where there is great swelling from effusion of fluid into joints, in which, as tar as the effecting the absorption of the fluid, blisters certainly possess a peculiar efficacy, I would answer both these questions in the negative, because by none of these remedies have we the same durable influence over these diseases as by issues used according to the plan I have recommended, which fact, I trust, is sufficiently proved in the explanation $I$ have given of their action; and again, because $I$ conceive that, used in this way, they are less liable to produce constitutional irritation than any other counter-irritant possessing any marked degree of control over serious affections of joints, and therefore may at any rate be as safely applied whenever this class of remedies is indicated.

For these reasons $I$ cannot but think that issues are too frequently left as the last resource, or their employment too long postponed for the trial of other less efficacious remedies, and that serious changes of structure are often allowed to take place before that is tried which has the greatest power of controlling these diseases.

I am obliged to speak thus generally, becanse, as I stated at the commencement, $I$ cannot in this paper enter into the application of this remedy in the various forms of diseases to which the joints are liable; but this I may say, that, used in the manner previously suggested, it may be applied, not only with safety, but often with advantage, in almost every form of disease, as soon as counter-irritants of any kind may be judiciously admissible, and that the valuable time which is commonly lost in the application of other less efficacions remedies, from the fear of exciting too much irritation by the too early employment of issues in the ordinary way with peas, may, by this mode of using the remedy, be often made available for establishing the cure of the patient and the reputation of the practitioner.

Charterhouse-square, April, 1847.

\section{ON THE EFFECTS OF ETHER INHALATION IN REFERENCE TO MESMERISM.}

BY CHARLES RADCLYFFE HALL, M.D., M.R.C.S.E., Holmes Chapel.

A LADX, aged twenty-four, desired to have two teeth extracted, under the influence of ether. She was evidently in great alarm, although she suppressed the ordinary manifestation of it. Her pulse was 120; her face alternately flushed and pale; and altogether her manner was that of subdued mental excitement. The mouth-piece of the apparatus was allowed to remain in the mouth for a short time before the stop-cock was turned. The patient evidently supposed that the process was going on, and after breathing common air for about a minute, partially removed the instrument, and said "she was sure she should die." The mouth-piece being re-adjusted, the ether was turned on. The patient drew in one full inspiration, and not appearing to commence expiration, the apparatus was removed. The eyes were wide open, the pupils not upturned but dilated; the jaws separated, and the head perfectly motionless, resting against the back of the chair; the gums were lanced, and a large and fast molar tooth extracted, with the key-lever, from the lower jaw. This was done leisurely, and perhaps occupied nearly a minute. The head was not held, but it remained perfectly unmoved, and the jaw retained the same open position. There was not the slightest sound, nor the least movement on the part of the patierit. A few seconds having elapsed, the lady closed her cyes and mouth, and became quite conscious. Her first remark was a question to the operator-" "How did he know when to begin, as she had given no sign ". When the bleeding had nearly ceased,- probably in about four minutes,-the ether was again used. The patient was now less alarmed, and had expressed her fear only lest the ether should not prove so effectual on a second trial. Two inspirations were taken before the fixed gaze declared that the influence was sufficient. A decayed canine tooth in the upjer jaw was broken, and only partially extracted. In about half a minute the patient came round, and was perfectly conscious; she had been aware of all that lad passed, but had not suffered the slightest pain; she laughed, congratulated herself on the result, and was rinsing out her mouth, when her grasp of the tumbler slackened, her face became pale, and lier head fell back; the pulse was frequent and very feeble; surface of the extremities cold. The patient was immediately laid on a sofa, with her head low, her face fanned, and her neck and forehead slapped with a wet towel. In a short time the said she felt, well but very sleepy. She was now raised, and took a wine-glass two-thirds full of port wine, but liept her eyes closed, declaring her inability to do otherwise. On raising the eyelid, the pupil was large but responsive to light; the lid dropping again immediately, in a passive, lax manner. The patient had all the appearance of a person so excessively drowsy as to be incapable of noticing or replying unless forcibly aroused, yet quite able then to do so with accuracy. Her head fell, and she quietly slipped back again into the recumbent position. Common smelling salts had no effect. An earthenware bottle of very hot water applied to the back of the legs was unnoticed. A question, repeated several times londly, was at last answered, always correctly, and with the additional expression of feeling great drowsiness. In this state of trance-like sleep, breathing without noise or effort, the patient remained about an hour. She now spoke more distinctly in answer to questions, and by degrees became attentive to those addressed to her in an ordinary tone of voice. She preferred having her head low, and always rolled it off the sofa-cushion, and bent it down to her chest. Her face was quite pale and statue-like, and her eyes closed during the ensuing two hours of conversation. At first, remarks intended to surprise and startle her were addressed, in the hope of exciting her mind. The answers elicited instantly showed, that so far from the patient being startled, her thoughts took up the cue of the remarks made. All anxiety as to the result being now removed by the momentary vivacity of her manner when speaking, and by the distinct intonation and marked emphasis with which she replied, the opportunity of observing some interesting psychical phenomena was irresistible. Without entering into details, it was evident that the mind was now at work in full force, but deprived of the guidance of correct consciousness. Mlemory was unlocked, reasoning acute, wit and humour in full play. To puzzle and confuse failed invariably, and met with a smart repartee. The same question, repeated after the lapse of an hour, was remembered distinctly, the patient inquiring why she was to reply twice to the same. Long pieces of poetry were recited correctly, and in excellent style; places graphically described, anecdotes admirably related, personal peculiarities quizzed, private character judged in a manner more pointed than complimentary, opinions discussed and arguments admitted, with a freedom as striking as in the present individual it is unusual. The suddenness with which a fresh suggestion appeared to change the entire current of thought-the perfect faith with which the lady seemed to believe she was addressing the party represented-the total absence of reserve in all her remarks, even when referring to personal matters upon which, when conscious, she would not have touched-were remarkable, and had evidently placed a very unusual power of penetrating into hidden thoughts in the hand of those around. The ladies present, and myself, were sufficiently convinced that the patient would unhesitatingly have divulged all her thoughts upon any subject suggested. Indeed, this extreme laying bare of the mind on each subject was the most striking of the phenomena observed.

At the expiration of about two hours, thus passed in conversation, the patient was told where she really was, and the circumstances which had occurred. She instantly understood where she was, but could not believe that she had undergone any operation, until her own finger was placed in the cavity eft by the extracted molar tooth. She was bewildered by this, as she could not at all recollect the occurrence. She 